\title{
GENETICAL, ENVIRONMENTAL AND PERSONALITY FACTORS INFLUENCING THE AGE OF FIRST SEXUAL INTERCOURSE IN TWINS
}

\author{
N. G. MARTIN*, L. J. EAVES* AND H. J. EYSENCK $\dagger$ \\ * Department of Genetics, University of Birmingham, and \\ $\dagger$ Department of Psychology, Institute of Psychiatry, Denmark Hill, London
}

(Received 21st June 1976)

\begin{abstract}
Summary. A study of MZ and DZ twins suggests that cultural differences are less important than individual environmental experiences in determining the age of first sexual intercourse. Certain personality factors are found to be correlated with this trait and there is also evidence that genetical differences may predispose individuals to cross this threshold at an earlier or a later age.
\end{abstract}

\section{Introduction}

A trend towards younger sexual initiation has been reported in recent years suggesting that the trait is currently influenced by cultural factors. It is reasonable to suspect, however, that in the past the age of first sexual intercourse could have been partly under genetical control and subject to natural selection. Although it would be premature to speculate about any relationship between age of first intercourse and reproductive fitness, there is little point in attempting to do so before genetical variation has been demonstrated. In this paper we report the findings of a recent twin study of this trait.

\section{Data}

As part of a study of the causes of variation in sexual and social attitudes and personality in twins (Martin \& Eysenck, 1976), we asked the question, 'At what age did you have your first intercourse (if virgin, leave blank)?'.

In December 1970, the 776 twin pairs voluntarily enrolled on the Twin Register of the Institute of Psychiatry in London and aged over 16 years were asked if they were willing to receive a postal questionnaire on sexual attitudes. Completed questionnaires were received from only one-third of the pairs asked to participate so there is ample scope for sample bias, even supposing the answers were accurate. The replies were anonymous and were matched into pairs by a ten-digit number 
agreed upon privately by each set of twins. Twins were asked (1) 'Do you differ markedly in physical appearance and colouring?' and (2) 'In childhood were you frequently mistaken by people who knew you?'. Kasriel \& Eaves (1976) have found that responses to these two questions give a diagnosis of zygosity which agrees very closely with that obtained by blood-grouping. Table 1 shows the composition of the twin sample whose responses are analysed here. They are predominantly young and middle class and the deficiency of DZ and male twins has almost become a universal feature of volunteer twin studies.

Table 1. Composition of the twin sample: range and mean age and percentage of individuals claiming to be middle class in each twin group

\begin{tabular}{|c|c|c|c|c|}
\hline \multirow[b]{2}{*}{ Twin group } & \multirow{2}{*}{$\begin{array}{l}\text { No of } \\
\text { pairs }\end{array}$} & \multicolumn{2}{|c|}{ Age } & \multirow{2}{*}{$\begin{array}{c}\% \\
\text { Middle class }\end{array}$} \\
\hline & & Mean & Range & \\
\hline MZ females & 95 & 28 & $18-52$ & 61 \\
\hline MZ males & 39 & 27 & $19-53$ & 61 \\
\hline$D Z$ females & 54 & .28 & $16-54$ & 66 \\
\hline $\mathbf{D Z}$ males & 17 & 24 & $17-36$ & 53 \\
\hline DZ opposite sex & 41 & 23 & $18-36$ & 72 \\
\hline Total & 246 & & & \\
\hline
\end{tabular}

In the best conducted survey of sexual behaviour in Britain, Schofield (1965, 1973) interviewed in 1963 and again in 1970 a large random sample of individuals born in 1943-46. The mean birth year of the twins is about 1943 so it is of interest to compare the surveys to obtain some idea of the representativeness of our sample. The cumulative percentages of individuals at risk who have had intercourse at a given age in the twin sample are compared with those from Schofield's study in Table 2.

The twins appear to be earlier starters than average, as might be expected in a volunteer sample. However, Schofield's survey excluded individuals married before

Table 2. Cumulative percentages of individuals at risk who have had sexual intercourse at a given age

\begin{tabular}{llllllll}
\hline & \multicolumn{3}{c}{ Females (\%) } & \multicolumn{3}{c}{ Males (\%) } \\
\cline { 2 - 7 } \cline { 4 - 7 } & \multicolumn{4}{c}{ Age (years) } \\
\cline { 2 - 7 } & 16 & 18 & 21 & 16 & 18 & 21 \\
\hline This study & 9 & 27 & 70 & 18 & 43 & 82 \\
Schofield & 5 & 17 & 71 & 14 & 34 & 75 \\
\hline
\end{tabular}


20 and it is also possible that a trend towards earlier intercourse increased the proportion of younger twins starting earlier (Schofield, 1965; Gorer, 1971; Ruzicka, 1975). Nevertheless, the twins do not appear to be grossly unrepresentative of the population in this aspect of sexual behaviour.

In analysing the responses to the question it is difficult to know what scores to give virgins. Any decision will introduce its own demographic biases and in an ideal study one would score everybody at a rather late age, say 50 . We have decided to score virgins as their age at the time of filling in the questionnaire and we shall discuss later the complication this introduces to the genetical analysis. The mean age of first intercourse and its standard deviation for the 339 females in the sample is $20.68 \pm 3.75$ and for the 153 males, $19.31 \pm 3.70$. These means include 75 female virgins (mean age 22.15 $\pm 4 \cdot 75$ ) and 31 male virgins (mean age 21.45 $\pm 4 \cdot 83$ ) so, referring to Table 1, it can be seen that the virgins are a much younger subsample than the non-virgins.

\section{Results and discussion}

The twins completed questionnaries on personality and sexual and social attitudes which are described by Eysenck (1976). They were scored on ten higher order factors and the analysis of these factor scores is discussed by Martin \& Eysenck (1976). In Table 3 we list the partial correlations (in which age is held constant) between age of first sexual intercourse and these ten factors, and with age itself.

None of the correlations is very high but we can see in both males and females that individuals who have intercourse earlier tend to have more libidinous, tough-minded attitudes and be more extraverted. This is what Schofield (1965)

Table 3. Partial correlations (age held constant) between àge of first sexual intercourse and attitudes and personality factor scores, and the correlation with age

\begin{tabular}{lrr}
\hline \multicolumn{1}{c}{ Factor } & Females & Males \\
\hline Sexual satisfaction & -0.12 & -0.16 \\
Sexual libido & -0.30 & -0.22 \\
Masculinity & -0.19 & -0.14 \\
Radicalism & -0.18 & 0.16 \\
Tough-mindedness & -0.19 & -0.10 \\
Emphasis & 0.05 & -0.12 \\
Psychoticism & -0.06 & 0.02 \\
Extraversion & -0.16 & -0.37 \\
Neuroticism & -0.09 & -0.02 \\
Lie & 0.16 & 0.07 \\
Age & 0.40 & 0.36 \\
\hline
\end{tabular}

Correlations significant at the $5 \%$ (2-tail) level are: females, $|r|>0.11$; males, $|r|>0.16$. 
predicted from his factor analysis of teenage attitudes. He isolated another dimension which he called permissiveness-restrictiveness in which sexually experienced females had much higher scores than experienced males. As he also predicted, this appears to correspond to Eysenck's radicalism scale on which we find that females who start intercourse early tend to be more radical while earlystarting males tend to be more conservative.

Multiple regression analysis of age of first sexual intercourse on age and the ten psychological factors reveals that for both males and females, age accounts for about one-sixth of the total variance and all the psychological factors account for about the same amount again. Thus, only about one-third of the total variation in age of sexual initiation can be accounted for by the aspects of cultural and personality variation measured here. We may attempt to achieve an overall partition of the variation into cultural, specific environmental and genetic sources by fitting models to the between and within pairs mean squares of the $\mathrm{MZ}$ and $\mathrm{DZ}$ twins.

Before attempting to fit models to the data, Jinks \& Fulker (1970) have advocated the use of scaling tests to see whether genetical and environmental effects are acting independently. The best known procedure is to test for a correlation between the sums of $\mathrm{MZ}$ pairs (which measure genetical, $G$, or cultural, $E_{2}$, differences between pairs) and their absolute differences (which measure individual environmental differences within pairs, $E_{1}$ ). This test has been found to be very powerful for detecting systematic interactions (Eaves et al., 1977).

When we apply this test to age of first sexual intercourse we find strong positive correlations between pair sums and absolute differences in both male and female MZ twins. Obviously this correlation is a consequence of scoring virgins as their present age and we are merely observing that opportunities for differences in expression of this trait increase with age. This is confirmed when we find the same - correlations between absolute pair differences and age. Because the difference within a twin pair depends upon its age, the results of a genetical analysis will clearly depend upon the age composition of the sample. Nevertheless, at any given age the difference between $\mathrm{DZ}$ twins will be due to both genetical and $E_{1}$ differences while the difference between $M Z$ twins will reflect only $E_{1}$ differences. Thus, while differences within pairs should increase with age in both types of twin, if there is any genetical influence on age of first sexual intercourse at any given age the differences between $\mathrm{DZ}$ twins should be greater on average than those between MZ twins.

Text-figure 1 shows the regression lines of absolute pair differences on age for both $\mathrm{MZ}$ and same-sex $\mathrm{DZ}$ twins. The regression slope for $\mathrm{MZ}$ females (0.104 \pm $0.035)$ was not significantly different from that for $M Z$ males $(0.082 \pm 0.066)$ and these data have been pooled, as have the $\mathrm{DZ}$ female $(0.207 \pm 0.058)$ and $\mathrm{DZ}$ male $(0.445 \pm 0 \cdot 151)$ regressions. The $\mathrm{DZ}$ opposite sex pairs have been excluded from the analysis because of the difference in means between males and females mentioned above.

It can be seen that the regression lines intersect at an age before much sexual activity has started. The pooled regression slope of $\mathrm{DZ}$ twins $(0.225 \pm 0.052$ is significantly greater $(P<0.02)$ than that of $\mathrm{MZ}$ pairs $(0.097 \pm 0.031)$ so that at 


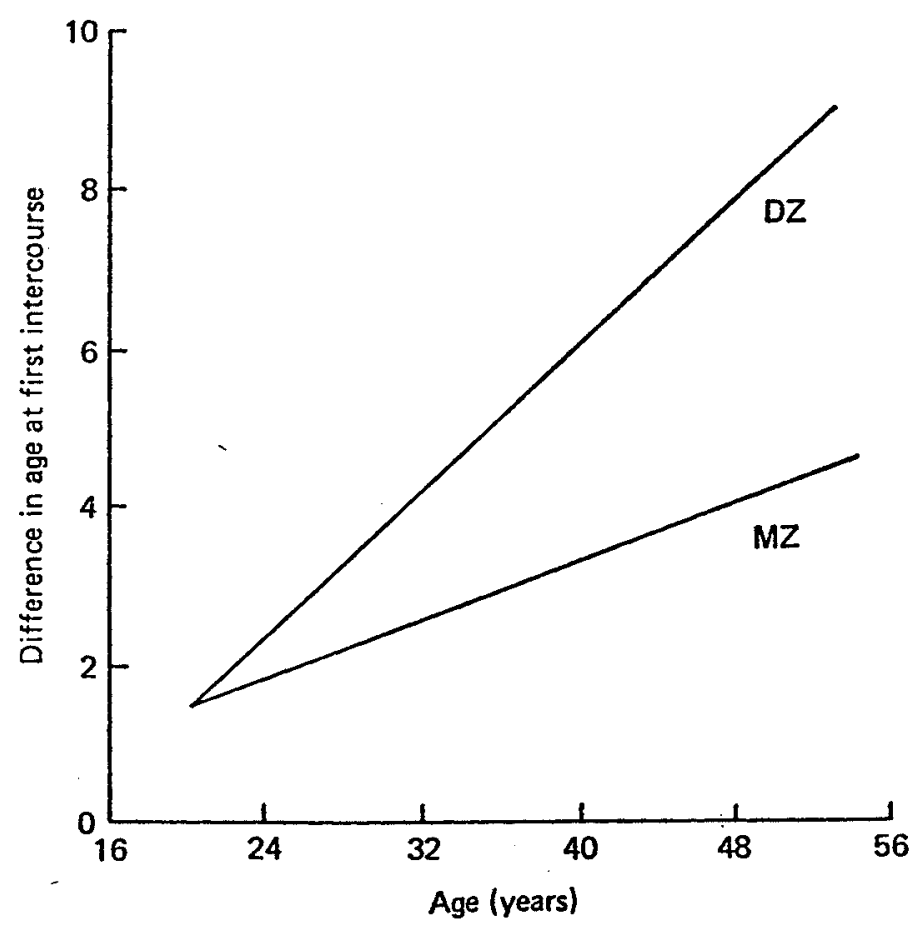

Text-fig. 1. Regression lines of absolute difference between twins in age of first sexual intercourse on age: for $\mathrm{MZ}$ twins, $y=-0.50+0.097 x$; for $\mathrm{DZ}$ twins, $\hat{y}=-2.96+0.225 x$.

every point above the age of $16 \mathrm{DZ}$ twins are on average more different than $\mathrm{MZ}$ twins.

If we translate the absolute differences to variances by squaring them and take the ratio of $\mathrm{DZ}$ within pair variance to its $\mathrm{MZ}$ equivalent as a rough index of the degree of genetic determination (given-no differential treatment within $\mathrm{MZ}$ and $\mathrm{DZ}$ twin pairs) we can see that this index increases with age.

The presence of this type of non-additivity should make us wary about fitting simple models which assume additivity but because the same-sex twin groups have similar age compositions we attempt to detect between families cultural effects $\left(E_{2}\right)$ influencing the age of first sexual intercourse in addition to the genetical and $E_{1}$ effects we have already shown to be present. If we have sampled the population adequately, then on the simplest possible model of the genetical component we should expect as much genetical variation $(G)$ within families as between families. Inadequate sampling or genetical non-additivity, such as might be expected if the trait is related to reproductive fitness, will tend to decrease the proportion of genetical variation between families while assortative mating will tend to increase it. In addition, cultural variation will increase between families variance but, in the case of twins reared together, will be indistinguishable from genetical effects acting between families. We introduce a third parameter $B$ which will take a positive value if the net differences between families exceed those predicted by the parameters $E_{1}$ and $G$ and will be negative if the differences are less than those predicted. 
Table 4 shows this model fitted to the mean squares from the analysis of variance of the twin groups. The fitting of models to twin data by weighted least squares has been described by Jinks \& Fulker (1970) and Eaves \& Eysenck (1975).

Table 4. Fit of the model with specific environmental $\left(E_{1}\right)$, genetical $(G)$ and between families $(B)$ effects to twin data for age of first sexual intercourse*

\begin{tabular}{|c|c|c|c|c|c|c|}
\hline \multirow[b]{2}{*}{ Mean square } & \multicolumn{3}{|c|}{ Model } & \multirow[b]{2}{*}{ df } & \multirow[b]{2}{*}{ Observed } & \multirow[b]{2}{*}{ Expected } \\
\hline & $E_{1}$ & $G$ & $B$ & & & \\
\hline MZ 9 Between & 1 & 4 & 2 & 94 & $17 \cdot 10$ & $21 \cdot 21$ \\
\hline Within & 1 & 0 & 0 & 95 & $7 \cdot 27$ & 8.07 \\
\hline MZ đ Between & 1 & 4 & 2 & 38 & 19.95 & $21 \cdot 21$ \\
\hline Within & 1 & 0 & $\mathbf{0}$ & 39 & $8 \cdot 40$ & 8.07 \\
\hline \multirow{4}{*}{$\begin{array}{l}\text { DZ } 9 \text { Between } \\
\text { Within } \\
\text { DZ o Between } \\
\text { Within }\end{array}$} & 1 & 3 & 2 & 53 & $21 \cdot 77$ & 17.00 \\
\hline & 1 & 1 & $\mathbf{0}$ & 54 & 14.55 & $12 \cdot 27$ \\
\hline & 1 & 3 & 2 & 16 & $18 \cdot 47$ & $17 \cdot 00$ \\
\hline & 1 & 1 & 0 & 17 & $13 \cdot 71$ & $12 \cdot 27$ \\
\hline & \multicolumn{3}{|c|}{$\begin{array}{r}x_{5}^{2}=5.53 \\
E_{1}=8.07 \pm 0.96 \\
G=4.21 \pm 1.98 \\
B=-1.84 \pm 3.49\end{array}$} & \multicolumn{2}{|c|}{$\begin{array}{l}P>0.05 \\
C=8.41 P<0.001 \\
c=2.13 P<0.05 \\
C=0.53 P>0.05\end{array}$} & \\
\hline
\end{tabular}

* For discussion of assumptions see text.

Although the model fits the combined male and female data adequately as judged by the non-significant chi-square, nearly all the deviation comes from the female data where the significantly greater total variance of $\mathrm{DZ}$ females suggests the presence of genetical effects of competition (Eaves, 1976). In fact, a competition model gives a marginally better fit to the female data $\left(\chi_{1}^{2}=3.25\right)$ and this tallies well with the finding of competition effects in the sexual satisfaction attitude scale for females in the same data (Martin \& Eysenck, 1976).

Simple models incorporating only the $E_{1}$ or $E_{1}$ and $E_{2}$ parameters fail to give an adequate fit to the female data and provide only poor accounts of the male data where the discriminating power is low. This indicates the presence of treatment differences or the need for a genetical parameter in our model but none of the model fitting gives any suggestion of cultural effects. In the fit of the $E_{1} G B$ model, significant specific environmental and genetical variation is detected but the non-significant negative value of $\hat{B}$ gives no evidence for any additional between families variance. However, we should expect some of the non-additive effects of the type we have described in these data to decrease the apparent variance between families so tending to cancel any cultural effects which may be present (Eaves et al., 1977). 
Nevertheless, we have had no difficulty in detecting significant cultural effects accounting for less than $30 \%$ of the variance in the libido, masculinity and radicalism attitudes scores in the same twins (Martin \& Eysenck, 1976). We have shown that about $16 \%$ of the variance in this sample is due to age differences (which could be part of $E_{2}$ ) between families and these two figures may give a reasonable guide to the size of possible cultural effects.

None of the models fits the data very well so we cannot discount the possibility that $\mathrm{DZ}$ twins are treated less uniformly than $\mathrm{MZ}$ twins with respect to this character, nor that our results are an artifact of poor sampling. However, the data do suggest that cultural influences may be less important in determining variation in the age of first sexual intercourse than specific environmental experiences of individual twins. The data may also be interpreted as suggesting that genetical differences, possibly expressed in part through differences in personality and attitudes, predispose an individual to cross this threshold at an earlier or a later age.

\section{Acknowledgments}

We are grateful to the twins for their co-operation in this study, to Judith Kasriel who collected the data, and to Professor J. L. Jinks for helpful criticisms. This work is supported by an MRC Programme Grant in Psychogenetics.

\section{References}

EAVES, L.J. (1976) A model for sibling effects in man. Heredity, 36, 205.

EAVES, L.J. \& EYSENCK, H.J. (1975) The nature of extraversion: a genetical analysis. J. pers. soc. Psychol. 32, 102.

EAves, L.J., LAST, K., MARTIN, N.G. \& JiNKS, J.L. (1977) A progressive approach to non-additivity-and genotype-environmental covariation in the analysis of human differences. $B r . J$. Math. Stat. Psychol. (in press).

EysENCK, H.J. (1975) Sex and Personality. Open Books, London.

GORER, G. (1971) Sex and Marriage in England Today. Nelson, London.

KASRIEL, J. \& EAVES, L.J. (1976) A comparison of the accuracy of written questionnaires with blood-typing for diagnosing zygosity in twins. J. biosoc. Sci. 8, 263.

JINKS, J.L. \& FULKER, D.W. (1970) A comparison of the biometrical genetical, MAVA and classical approaches to the analysis of human behaviour. Psychol. Bull. 73, 311.

MARTIN, N.G. \& EysENCK, H.J. (1976) Genetical factors in sexual behaviour. In: Sex and Personality. By H. J. Eysenck. Open Books, London.

RuzickA, L.T. (1975) Non-marital pregnancies in Australia since 1947. J. biosoc. Sci. 7, 113.

Schofield, M. (1965) The Sexual Behaviour of Young People. Longmans, London.

Schofield, M. (1973) The Sexual Behaviour of Young Adults. Allen Lane, London. 